\title{
COMPARAÇÃO DA PRODUÇÃO DE ETANOL POR Zymomonas mobilis EM MEIO DE MELAÇO DE CANA-DE-AÇÚCAR PURO E PRÉ-TRATADO COM INVERTASE
}

\author{
FRANCIELLE GUILMAN 1 \\ JOÃO BATISTA BUZATO 2 \\ MARIA ANTONIA P. COLABONE CELLIGOI²
}

GUILMAN, F.; BUZATO, J. B.; CELLIGOI, M. A. P. C. Comparação da produção de etanol por Zymomonas mobilis em meio de melaço de cana-de-açúcar puro e pré-tratado com invertase. Semina: Ci. Biol. Saúde, Londrina, v. 20/21, n. 2, p. 39-43, jun. 1999/2000.

\begin{abstract}
RESUMO: Foi estudada a produção de etanol por Zymomonas mobilis em melaço de cana-de-açúcar e melaço pré-tratado com invertase. Os cultivos foram realizados em batelada por 48 horas, em melaço a $120 \mathrm{~g} / \mathrm{L}$ de açucares redutores totais e temperatura constante de $30^{\circ} \mathrm{C}$. A produção de etanol e consumo de açucares foram determinados. A melhor produção de etanol foi $39,5 \mathrm{~g} / \mathrm{L}$. no cultivo em melaço prétratado com e $1 \mathrm{~mL}$ de invertase por 30 minutos. Representando um aumento de $52,8 \%$ em relação ao cultivo sem adição de invertase.
\end{abstract}

PALAVRAS-CHAVE: Zymomonas mobilis; Etanol; melaço de cana-de-açúcar.

\section{INTRODUÇÃO}

Zymomonas mobilis tem sido alvo de inúmeras pesquisas devido ao seu alto potencial fermentativo que utiliza sacarose, glicose e frutose pela via de Entner-Doudoroff resultando em grande produção de etanol comparável ou mesmo superior ao das leveduras. (Kannan et al., 1998; Stanley \& Pamment, 1992; Yanase et al., 1992),

Vários substratos podem ser utilizados como fonte de carbono na realização dos processos fermentativos. Geralmente procura-se estabelecer um meio de baixo custo e favorável ao desenvolvimento do microrganismo. O melaço de cana-de-açúcar é um dos principais substratos utilizados em fermentação que apresenta sacarose como principal fonte de carbono. (Park \& Barati, 1992; Duarte et al., 1996; Diez \&Yokoya 1996).

A produção de etanol a partir de meios ricos em sacarose pela $Z$ mobilis é consideravelmente reduzida pela formação de subprodutos tais como levana e sorbitol, assim o pré-tratamento do melaço com invertase pode reduzir a formação desses produtos e aumentar a produção de etanol. (Bassetti,1995)

Invertase ou frutofuranosidase (E.C. 3.2.126) é uma enzima produzida por várias plantas e microrganismos, mas aquelas produzidas por leveduras têm importância industrial, que hidrolisa a sacarose, um dissacarídeo não redutor, em $D$ glicose e D - frutose (Bergamasco, 1989).

A quebra catalisada pela invertase de Saccharomyces cerevisiae tem a vantagem de produzir um produto de melhor qualidade, já que não resulta subproduto indesejável, proveniente de reações paralelas e não ocorre perda de açúcares totais (Bassetti, 1995).

Considerando que Zymomonas mobilis ATCC 29191 pode durante o processo fermentativo levar uma hidrólise incompleta da sacarose resultando numa menor formação de etanol, (Doelle \& Doelle,1990). Este trabalho teve como objetivo pré tratar o melaço de cana-de-açúcar com invertase de Saccharamyces cerevisiae para melhorar a produção de etanol por Zymomonas mobilis.

\section{MATERIAIS E MÉTODOS}

Microrganismo: Zymomonas mobilis ATCC 29191 foi mantida em meio líquido contendo glicose 20g/L; extrato de levedura 10g/L; $\left(\mathrm{NH}_{4}\right)_{2}$ $\mathrm{SO}_{4} 1 \mathrm{~g} / \mathrm{L} ; \mathrm{KH}_{2} \mathrm{PO}_{4} 2 \mathrm{~g} / \mathrm{L} ; \mathrm{MgSO}_{4} \cdot 7 \mathrm{H}_{2} \mathrm{O} 0,5 \mathrm{~g} / \mathrm{L}$; $\mathrm{FeSO}_{4} 0,5 \mathrm{~g} / \mathrm{L}$ e peptona $5 \mathrm{~g} / \mathrm{L}$. Após incubação por 24 horas a $30^{\circ} \mathrm{C}$, as culturas foram mantidas a $4^{\circ} \mathrm{C}$ e reativadas a cada 30 dias.

\footnotetext{
1 Aluna do Curso de Química - Universidade Estadual de Londrina

2 Docentes do Departamento de Bioquimica, Centro de Ciências Exatas, Universidade Estadual de Londrina, Caixa Postal 6001 , Londrina/Pr, CEP 86051-990, E-mail: celligoi@inbrapenet.com.br
} 
Matéria Prima: Melaço de cana-de-açúcar foi utilizado como fonte de carbono. Cedido pela Cooperativa Agrícola de Rolândia - PR

Invertase: A enzima foi extraida da levedura de panificação, Saccharomyces cerevisiae, segundo Nepomuceno (1998). Apresentando atividade de $267,609 \mathrm{Umol} / \mathrm{mL} / \mathrm{min}$,

Meios de fermentação: Melaço de cana-deaçúcar diluído a $12 \%$ de açúcares redutores totais (ART), e melaço pré-tratado com $1 \mathrm{ml}$ da solução de invertase por 15 e 30 minutos.

Inóculo: O inoculo foi preparado cultivando a bactéria em meio de preservação por 24 horas a $30^{\circ} \mathrm{C}$. Para a propagação do inoculo, $10 \%(\mathrm{v} / \mathrm{v})$ desta cultura foi transferida para novo meio e incubado nas mesmas condições.
Fermentações: As fermentações foram realizadas em frascos erlenmeyer com $50 \mathrm{~mL}$ dos meios de melaço ou melaço com invertase, $\mathrm{pH} 6,0$ por 0 , 24 e 48 horas a $30^{\circ} \mathrm{C}$, cultivo estático. Após cada tempo as fermentações foram interrompidas por centrifugação e do líquido metabólico foram quantificados os açúcares redutores e redutores totais, por somogyi e Nelson, segundo Amorim, (1982) e a produção de etanol por Kaye \& Haag (1954).

\section{RESULTADOS E DISCUSSÃO}

Os resultados obtidos da fermentação em batelada, por Zymomonas mobilis ATCC 29191, utilizando como substrato melaço de cana-deaçúcar a $12 \%$ e pré-tratado com invertase estão apresentados na Tabela 1.

Tabela 1 - Resultados da fermentação de Zymomonas mobilis ATCC 29191 em meio de melaço de canade-açúcar a $12 \%$ e melaço pré-tratado com 1 de invertase por 15 e 30 minutos.

\begin{tabular}{|c|c|c|c|c|c|c|c|c|}
\hline TRATAMENTOS & $\begin{array}{l}\text { TEMPO } \\
\text { (Horas) }\end{array}$ & $\begin{array}{c}\text { ART } \\
\text { RESIDUAL } \\
(\mathrm{g} / \mathrm{L})\end{array}$ & $\begin{array}{c}\text { AR } \\
(g / L)\end{array}$ & $\begin{array}{l}\text { CONS } \\
\text { AÇU }\end{array}$ & $\begin{array}{l}10 \mathrm{DE} \\
\mathrm{RES} \\
{ }_{1}\end{array}$ & $\begin{array}{c}\text { ETANOL } \\
(p) \\
(g / L)\end{array}$ & $\begin{array}{l}\text { Ypr } \\
(\%)\end{array}$ & $\begin{array}{c}Y p \\
(g / L . h)\end{array}$ \\
\hline $0 \mathrm{~mL}$ & 0 & 116.40 & 26.6 & 0 & 0 & 0 & 0 & 0 \\
\hline $0 \mathrm{~mL}$ & 24 & 90.1 & 54.5 & 26.3 & 22.15 & 20.48 & 33.5 & 0.85 \\
\hline $0 \mathrm{~mL}$ & 48 & 26.45 & 5.95 & 89.95 & 77.05 & 25.85 & 41.75 & 0.54 \\
\hline $1 \mathrm{~mL}+15$ & 0 & 111.0 & 31.7 & 0 & 0 & 0 & 0 & 0 \\
\hline $1 \mathrm{~mL}+15$ & 24 & 66.4 & 17.3 & 44.6 & 40.2 & 29.47 & 49.96 & 1.23 \\
\hline $1 \mathrm{~mL}+15$ & 48 & 39.5 & 6.6 & 71.5 & 64.4 & 32.34 & 54.8 & 0.67 \\
\hline $1 \mathrm{~mL}+30$ & 0 & 109.0 & 36.2 & 0 & 0 & 0 & 0 & 0 \\
\hline $1 \mathrm{~mL}+30$ & 24 & 64.4 & 15.7 & 44.6 & 41.0 & 31.26 & 53.0 & 1.3 \\
\hline $1 \mathrm{~mL}+30$ & 48 & 46.8 & 10.0 & 61.2 & 56.1 & 39.5 & 66.97 & 0.82 \\
\hline
\end{tabular}

O meio de melaço, pré-tratado com $1 \mathrm{~mL}$ de invertase por 30 minutos elevou a concentração de açúcares redutores de 26,6 para $36,2 \mathrm{~g} / \mathrm{L}$, disponibilizando mais açúcares para a produção de etanol pela bactéria.
As Figuras de 1, 2 e 3 mostram a cinética do consumo de açúcares e a produção de etanol que tanto no melaço puro quanto no tratado com $1 \mathrm{~mL}$ de invertase por 15 e 30 minutos, a produção de etanol foi melhor em 48 horas de cultivo.. 


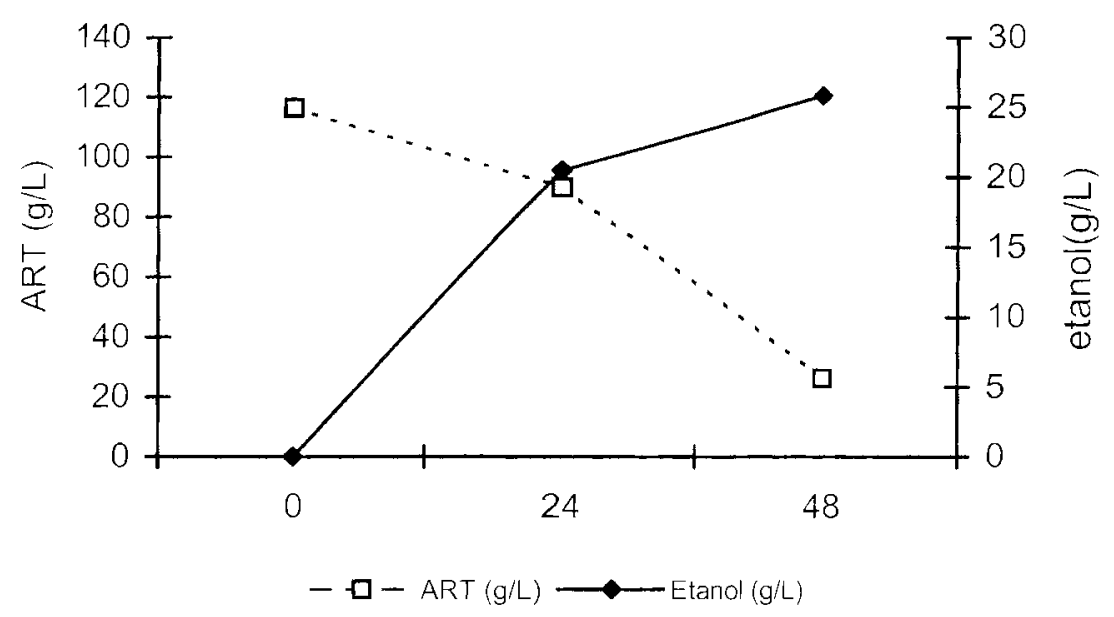

Figura 1 - Avaliação do Açúcar residual $(\mathrm{g} / \mathrm{L})$ e a produção de etanol $(\mathrm{g} / \mathrm{L}$ ) por Zymomonas mobilis em melaço a $12 \%$.

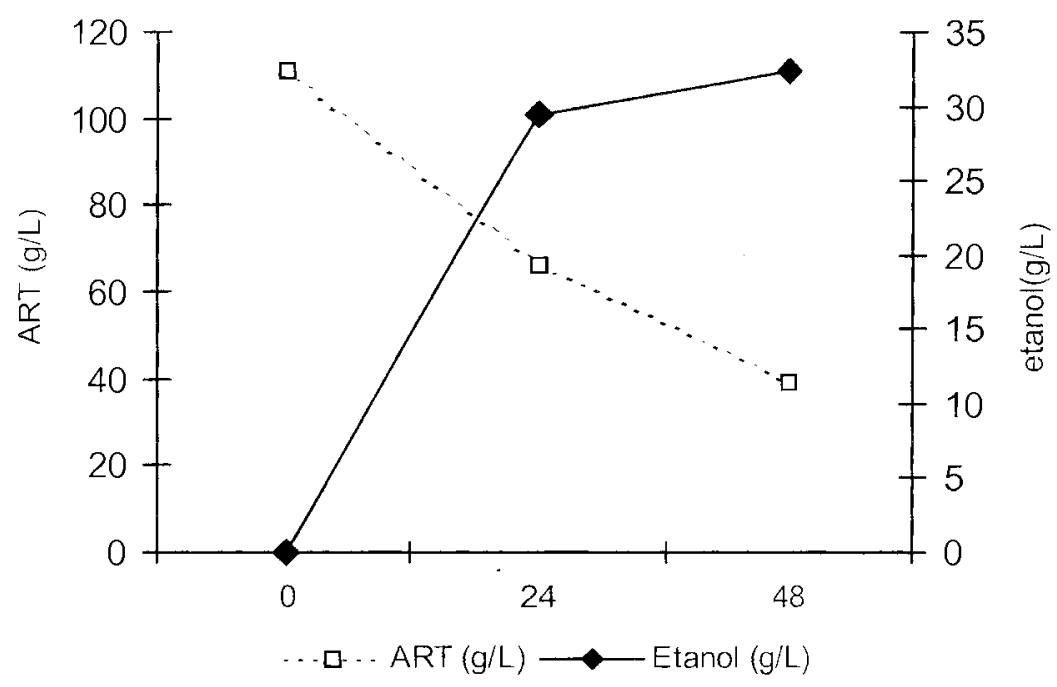

Figura 2 - Avaliação do Açúcar residual (g/L) e a produção de etanol (g/L) por Zymomonas mobilis em melaço a $12 \%$ pré-tratado com $1 \mathrm{~mL}$ de invertase por 15 minutos.

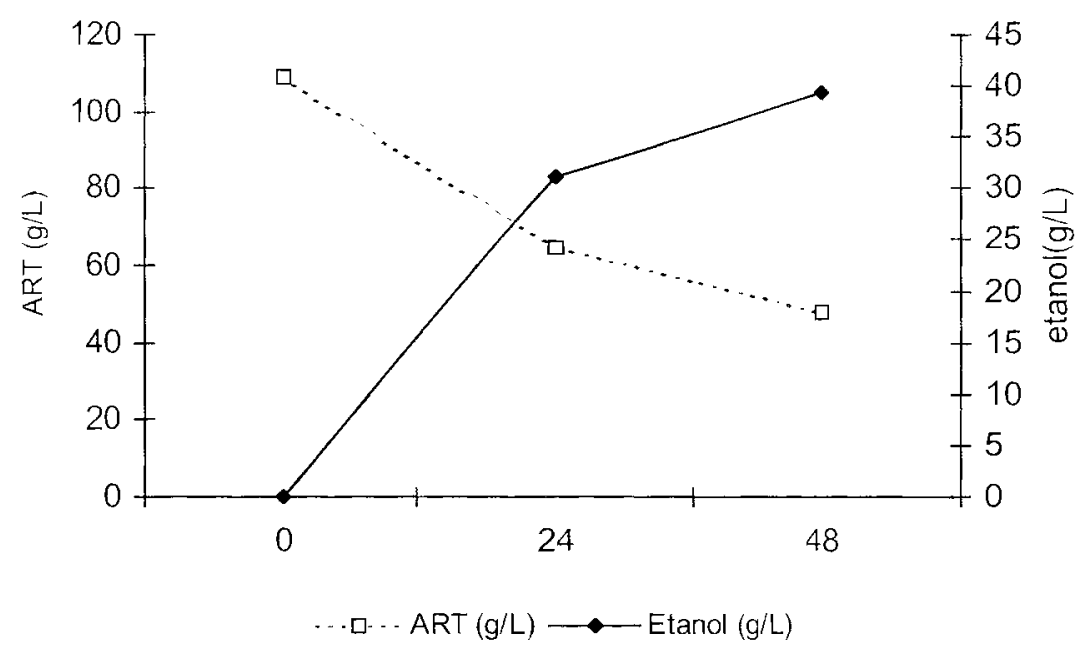

Figura 3 - Avaliação do Açúcar residual ( $g / L$ ) e a produção de etanol ( $g / L$ ) por Zymomonas mobilis em melaço a $12 \%$ pré-tratado com $1 \mathrm{~mL}$ de invertase por 30 minutos. 
A melhor produção de etanol $39,5 \mathrm{~g} / \mathrm{L}$ foi obtida no cultivo utilizando melaço suplementado com $1 \mathrm{~mL}$ de invertase por 30 minutos em 48 horas de cultivo (Figura 3), representando um aumento de $52,8 \%$ em relação ao cultivo sem tratamento com invertase no mesmo tempo de fermentação.

As melhores produtividades de etanol foram 1,23 e $1,3 \mathrm{~g} / \mathrm{L}$.h em 24 horas de cultivo nas diferentes condições estudadas. A adição de invertase aumentou significativamente este parâmetro quando comparado ao controle (Tabela 1).

Segundo Menezes (1980), o rendimento industrial do processo depende, em grande parte, dos nutrientes presentes no mosto de fermentação, e a redução do tempo é importante para aumentar a produtividade.

O rendimento da fermentação ( $\mathrm{Ypr} \%$ ) foi melhor nos cultivos com invertase atingindo $54,8 \%$ e $66,97 \%$ com 15 e 30 minutos de tratamento respectivamente.
Doelle \& Doelle (1990) justificam que no melaço ocorrem menores rendimentos devido ao grande número de compostos inorgânico e outros materiais que inibem o processo.

A Figura 4 traz uma comparação da produção de etanol dos experimentos desenvolvidos, mostrando que a bactéria apresentou um comportamento positivo, no sentido de aumentar a produção de etanol com o aumento do tempo de tratamento do melaço com a invertase.

Durante as fermentações o $\mathrm{pH}$ praticamente não se alterou, permanecendo próximo de $\mathrm{pH}$ 6,0. Este comportamento é totalmente diferente quando sacarose é utilizada para fermentação; nesse caso, sofre uma queda gradual. O melaço apresenta, portanto, efeito tamponante. Segundo Diez \& Yokoya (1996) esta ação estabilizadora do pH depende da composição química do melaço.

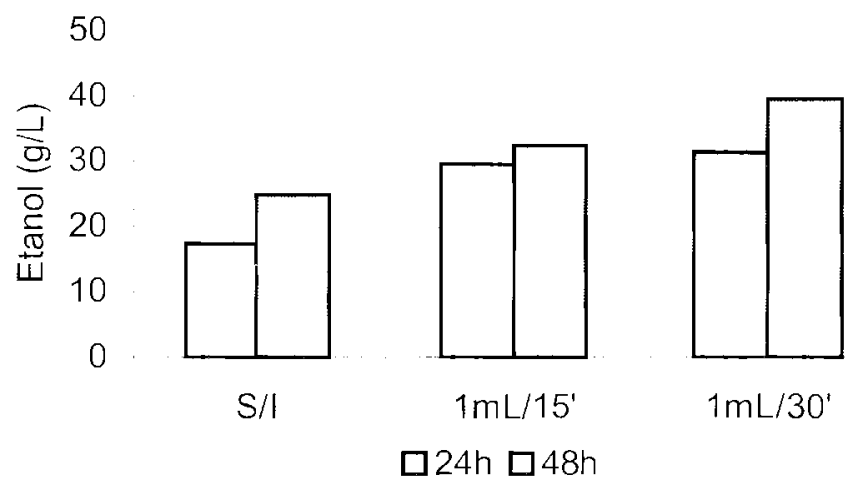

Figura 4 - Comparação da produção de etanol ( $\mathrm{g} / \mathrm{L}$ ) em melaço $12 \%$ e melaço pré-tratado com invertase nos tempos de 24 e 48 horas.

\section{CONCLUSÃO}

Os resultados obtidos nestes experimentos permitem relatar que: o pré-tratamento do melaço de cana-de-açúcar com invertase aumentou a disponibilidade de açúcares redutores, que conseqüentemente aumentou a produção de etanol por Zymomnas mobilis.
A melhor condição para a produção de etanol foi com melaço pré-tratado com $1 \mathrm{~m} \mathrm{~L}$ de invertase por 30 minutos e 48 horas de cultivo. A melhor produtividade foi em 24 horas também em melaço pré-tratado. Assim esta técnica pode representar uma alternativa viável, para melhorar a produção de etanol, no meio de melaço de cana-de-açúcar. 
GUILMAN, F.; BUZATO, J. B.; CELLIGOI, M. A. P. C. Comparasion of ethanol production by Zymomonas mobilis utilizing sugar - cane molasses in "natura"and pré-treated with invertase. Semina: Ci. Biol. Saúde, Londrina, v. 20/21, n. 2, p. 39-43, jun. 1999/2000

ABSTRACT: The comparison of ethanol production by Zymomonas mobilis utilizing sugar-cane molasses in "natural" and pre-treated with invertase has been carried out. Batch fermentation were performed for 48 hours and sugar concentration was $120 \mathrm{~g} / \mathrm{L}$ at $30^{\circ} \mathrm{C}$. The highest ethanol concentration was $39.5 \mathrm{~g} / \mathrm{L}$ when molasses was pre-treated with $1 \mathrm{~mL}$ of invertase. The value is $52,8 \%$ higher than molasses in "natural" was used.

KEY WORDS: Zymomonas mobilis; Ethanol; sugar-cane molasses.

\section{REFERÉNCIAS BIBLIOGRÁFICAS}

AMORIM, H. V.: ZAGO, E. A.; OLIVEIRA, A. J. Novos métodos analiticos para controle da fermentação alcoólica. São Paulo: Sociedade Brasileira de Microbiologia, 1982. 58 p. Série: Manuais Técnicos e Cientificos.

BASSETI, F.J. Caracterização da invertase imobilizada em silica de porosidade controlada e sua aplicação em reator de leito fixo e fluidizado. Londrina, 1995. Dissertação (Mestrado em Ciência e Tecnologia de Alimentos) Universidade Estadual de Londrina.

BERGAMASCO, R. Cinética da Hidrólise de sacarose pela invertase: modelagem matemática. Londrina, 1989. Dissertaçāo (Mestrado em Ciência e Tecnologia de Alimentos) - Universidade Estadual de Londrina,

DIEZ , J. C.; YOKOYA, F. Efeito da temperatura e $\mathrm{pH}$ na produção de etanol e levana durante a fermentação de sacarose por Zymomonas mobilis. Arquivos de Biologia e Tecnologia. v. 39, n. 1, p. $129-137,1996$

DOELLE, M. B.; DOELLE, H. M. Sugar-cane molasses fermentation by Zymomonas mobilis. Applied Microbiology and Biotechnology. v. 33, p. 31-35, 1990

DUARTE, J. C.; CELLIGOI, M. A. P. C.; BUZATO, J. B. Fermentação alcoólica por Zymomonas mobilis CP4 ou por Saccharomyces cerevisiae em caldo-de cana com e sem suplemento lipidico. Arquivos de Biologia e Biotecnologia, v. 39, n. 2 , p. $285-293,1996$
KANNAN, T.R:; SANGILIYANDI, G; GUNASEKARAN, P. Improved ethanol production from sucrose by a mutant of Zymomonas mobilis lacking sucrases in immobilized cell fermentation. Enzyme and Microbial Technology. v. 22, p.179-184, 1998.

KAYE, S.; HAAG, H.B. Determination of alcoholic content. Journal Forenses Medical. v.1. p. 373, 1954.

MENEZES, T.J.B. de. Etanol. o combustivel do Brasil. São Paulo: Agronômica Ceres, 1980. 233p,

NEPOMUCENO, M.F. Bioquimica experimental. Piracicaba: UNIMEP, 1998 Cinética enzimática II. Cinética enzimática da invertase. p.57-60.

PARK, Y. K.; BARATI, J. C. Continuous ethanol production from sugar beet molasses using osmotolerant mutant strain of Zymomonas mobilis. Journal of Fermentation and Bioengineering. v.73, n.1, p. 16-21, 1991.

STANLEY, G. A.; PAMMENT, N. B. Transport and intracellular accumulation of acetaldehyde in Saccharomyces cerevisiae. Applied Microbiology Biotechnology. v. 38 , p. 656-663, 1992

YANASE, H.; IWATA, M.; NAKAHIGASHI, R.; KITA, K.; KATO, N.; TONOMURA, K. Purification, crystallisation and properties of the extracelular levansucrase from Zymomonas mobilis. Bioscience, Biotechnology and Biochemistry, v. 56, p. 1335-1337, 1992. 